\title{
Crypto-Preservation and the Ghost of Andy Warhol
}

\author{
Jon Ippolito $^{1}$
}

1 University of Maine; jippolito@maine.edu

\begin{abstract}
For its enthusiasts, the blockchain is an archivist's dream come true: an immutable historical record that is publicly accessible and immune from censorship. Proposals like Juried Protocol Galleries could enable bots to compute the provenance of digital artworks and their appearance in exhibitions and publications. Distributed file systems like IPFS claim to store creative works in a redundant, networked fashion outside the control of any single cloud provider. Projects designed to work with blockchains like Filecoin and Arweave propose a dedicated cryptocurrency as financial incentive to support the cost of governing and sustaining this "permaweb." As dreamy as this picture sounds, many of these promises depend on technologies that have yet to be sufficiently developed or adopted. Rather than forecast the future, we can separate the hype from the reality in the present day by examining a real-life example, namely the 2021 auction of Andy Warhol's digital art with NFTs. This essay will focus less on blockchain's general promise as a preservation medium and more on the particular case of the digital Warhols, which both in form and spirit would seem a perfect application of NFTs to preserve historically important works of digital art. Which promises of the crypto-dream of permanent access to digital heritage ring true for this case study, and which are overblown?
\end{abstract}

Keywords: digital art; Andy Warhol; Yves Klein; Pop art; blockchain; NFT; digital preservation; variable media; authenticity; networked storage; migration; cryptocurrency; Amiga

\section{The rediscovery and tokenization of Warhol's digital art}

The 2014 recovery of lost images created by Andy Warhol on diskettes from a 1985 Amiga computer gave digital art the imprimatur of an art-world celebrity. [1] This mainstream recognition was only possible because the conservators of those images, a team of grad students from the Carnegie Mellon University Computer Club, translated their idiosyncratic Propaint format into upscaled JPEGs that the Warhol Foundation could post online to let the public know about this amazing discovery.

Six years later, at one of the first peaks in the craze over NFTs (Non-Fungible Tokens), the owners authorized Christie's to sell the migrated files via unique crypto-tokens. Despite their clear deviation from the original formats, NFTs for these "improved" images fetched \$3.3 million at auction. Echoing the claims of NFT champions, Christie's CEO bragged that the sale represented "the possibility to secure the uniqueness and authenticity of this work on the blockchain," while a representative of the Warhol Foundation called it a "watershed moment in the history of digital art." [2]

\section{Could NFTs secure the authenticity of Warhol's digital works?}

To evaluate the claim that tokenizing these digital images will help preserve them for posterity, it's important to remember what you get when you buy an NFT.

\section{1. . NFTs don't convey rights to media}

Unlike collecting unique originals, collecting a non-fungible token doesn't change the status of an image associated with it. An NFT is just a transaction written to a blockchain, which is essentially a big receipt in the sky: visible by all and nearly impossible to tamper with. This receipt shows the buyer, the seller, and the transaction amount in a cryptocurrency like Ether. Except in the rare case of on-chain art, the other important datum on the 
receipt is a link to a metadata file outside of the blockchain. That metadata file, in turn, includes another link to the artwork itself, which lives somewhere else on the Internet. Further weakening this shaky connection between the token and the artwork is the current absence of any statutory or case law to enforce an NFT contract.

When you buy an NFT, you don't buy the original asset so much as you buy the idea of owning that asset. While some marketplaces may add legal constraints to the purchase, the NFT itself doesn't give you exclusive or non-exclusive rights to the original asset. That's why comedian John Cleese could make an NFT of the Brooklyn Bridge and tennis player Oleksandra Oliynykova could sell a patch of her skin. Legally speaking, NFTs are closer to a collectable that supports your favorite sports team: just because you own a Los Angeles Lakers coffee mug doesn't mean you own a basketball franchise. This tenuous relationship prompts some to question why anyone would buy an NFT when there is no almost nothing received in return.

The fine print of the Christie's conditions of sale make this clear by explicitly disavowing any rights the NFT buyer might have over the Warhol images, apart from the right to "display the digital asset for your own personal, non-commercial use." Christie's contract also "does not represent, warrant, or guarantee the persistence, security, stability, integrity, or continued existence of any lot or digital asset." So much for securing longterm access to the artwork.

As if to justify this blatant disregard for the historical record, the contract identifies a litany of potential failure points. For the asset, these include deficient third-party hosts. For the NFT, these include unfavorable regulatory determinations, corrupted digital wallets, $51 \%$ attacks, forks, and mysterious "blockchain malfunctions." For a technology billed as an ironclad guarantee of ownership, NFTs have a longer list of disclaimers than a Viagra ad. [3]

Even if all goes as planned, your "contract" is not exclusive: given that no rights are conveyed by a typical NFT, there's nothing to stop John Cleese (or any of his fellow Monty Python buddies) from minting and selling another NFT of the Brooklyn Bridge. So unlike normal receipts, NFTs require no obligation of the buyer or seller; they are just a nominal transaction on a distributed ledger that everyone can see. They are as close as you can get to pure ownership, stripped of any attending rights or responsibilities.

\subsection{Storage is not preservation}

For the sake of argument, imagine that Christie's ripped up its existing conditions of sale and replaced it with a contract that conveys legal rights and a guarantee of access to the media file. Sadly, even this improbable scenario wouldn't be enough to safeguard Warhol's digital art for the future. As counterintuitive as it may seem, access to immutable bits doesn't ensure access to the original artistic experience. To see why, we need to understand that, despite the blockchain's apparent permanence, neither storing the original file nor migrating it to the latest format is sufficient to preserve its authenticity.

Leaving aside its numerous economic and ecological faults [4], the blockchain does in fact provide secure data storage. In the event that Christie's lawyers have an improbable a change of heart and convey rights to Warhol's media assets outside of the chain, economic drivers may also extend the longevity of access to assets that have attained a high market value. Collectors of digital Warhols may be more likely to "pin" them on a peerto-peer network like IPFS (InterPlanetary File System). And protocols such as Filecoin and Arweave propose to offer cryptocurrencies as financial incentive to keep the computers that host these assets humming.

Even digital assets that don't have the stratospheric valuation of a Warhol self-portrait may persist if they can be stored directly on the blockchain, and therefore conveyed legally and accessed directly via an NFT. While this is impractical for any decent-sized raster image or movie, a handful of kilobytes is plenty for many artists whose images are generated from code. Art Blocks is an example of a marketplace designed to help creators store generative code inside blockchain smart contracts. One artist who's minted NFTs on Art Blocks is Dmitri Cherniak, who created the images in his Ringers collection by writing 
JavaScript that generates 1000 ways of wrapping a virtual string around a set of virtual pegs. [5] The theory behind selling generative NFTs is that the code can be run as long as the chain is viable.

Unfortunately networked storage, incentivized or not, has many potential failure points. It's true that distributed solutions such as IPFS and Arweave are less prone to the kind of catastrophic failure that caused MySpace to lose 50 million works in 2019. However, peer-to-peer systems are more likely to suffer gradual degradation due to peers abandoning the system; how many Napster or Gnutella nodes are still in use today?

Even if the bits of these files persisted, they would still be vulnerable to the "Linear A problem" for digital preservation. Linear A is a Minoan script from 1500 BCE that survives on fired-clay tablets such as the Phaestos discs from Crete. Thanks to the durable medium they were sculpted into, the characters are clear and easily distinguished. Yet the immutability of the medium hasn't helped anthropologists decipher the meaning of this ancient alphabet, because none of the context has survived along with these discs. We may know for sure that the first two characters on a disc are a squiggle followed by an arrow, but we have very little idea what those symbols meant.

The same fate will befall any computer program or image even if their ones and zeros are preserved for anthropologists of the future. The problem is compounded for future historians by the many layers of software and hardware needed to decode digital symbols. Imagine, for example, that the technology for minting NFTs and saving them to distributed file networks had existed ten years ago. At that point, a dominant medium for the kinds of animated graphics commonly seen in today's NFTs would have been Adobe Flash. Unfortunately, due to increasing concerns about security and memory usage, Flash has since been superseded by languages such as HTML5. As a result, Flash files no longer run on any current browser or operating system. So all of the Flash graphics and animations sitting on Arweave or IPFS and sold as NFTs would now be unreadable, regardless of whether their bits were "immutable."

\subsection{Migration can lead to losses in translation}

To be sure, enterprising preservationists have devised creative strategies for resurrecting obsolete files beyond storage, including migration, emulation, and reinterpretation. Knowing which of these strategies to apply, however, requires a case-by-case examination. Migration, or converting files to newer formats, is the most prevalent strategy today for resurrecting obsolete material. Unfortunately for digital art, migration always requires some sacrifice of the look and feel of the original work. In the case of Warhol's NFTs, migration destroyed much of what made the originals prized in the first place.

Warhol saved his brightly colored sketches from 1985 onto a floppy disk now owned by the Warhol Museum. Those original images took the form of an idiosyncratic Amiga format composed of 320 by 200 non-square pixels. While no more than a postage stamp by the standard of today's $4 \mathrm{k}$ monitors, these images are historically important precisely because they represent a primitive ancestor to today's robust digital graphics.

With the permission of the Warhol Museum, the CMU Computer Club created versions of the files at 4,500 by 6,000 pixels for use as press materials, never suspecting that the Foundation would someday choose to tie their NFT sales to these deviations from the vintage assets. To historians of digital media, these upscaled pixels are a distortion of the original. To sell "improved" versions of Warhol's 1985 Propaint images in the form of 20megapixel TIFFs is like selling "improved" 1845 silver photographic plates by Louis Daguerre in the form of wall-sized Giclee prints. So not only was there no legally mandated access to the original when the Warhol NFTs were sold, but in fact the asset described in the associated metadata had been significantly modified from the original asset anyway.

To be sure, for some artists and artworks, such deviations from the original might be acceptable for future viewings. Or, instead of migration, an artist might prefer emulation, though emulation has its own nuances such as resolution, color depth, and image interpolation. Other artists might prefer reinterpretation, a strategy whereby the work might be regenerated from scratch each time--a tactic explored by on-chain NFT artists such as 
DEAFBEEF. The problem is that there's no way to know which preservation strategy to apply without detailed information from the artist and other experts on the work.

\subsection{Missing preservation guidelines}

Fortunately, over the past half-century savvy gallerists and conservators have explored protocols to help clarify artists' preferences on the myriad questions for how a work should be preserved. Certificates of authenticity are legal instruments invented in the 1960s by artists and collectors to convey works that could not be physically exchanged. When Giuseppe Panza di Biumo bought a Sol LeWitt wall drawing meant to be painted over and redrawn, the rights to this work were conveyed by a piece of paper with the artist's signature. Certificates of authenticity are still used to this day to represent works like ephemeral performances, installations, and conceptual art, whose physical assets are interchangeable or otherwise insufficient to re-exhibit the work. Such certificates are also used to transfer ownership of video installations and other media art, whose ephemerality is an inevitable result of technological obsolescence.

While NFTs are often compared to certificates of authenticity, there are significantly differences. Apart from the fact that NFTs typically transfer ownership of a blockchain pointer rather than the work itself, certificates have been critical to the preservation of contemporary art because they often include diagrams and other instructions for re-constructing the work. These range from Sol LeWitt's minimalist instructions for his wall drawings ("10,000 lines about 5 inches long") to Bill Viola's exacting stipulations for his video installations, which specify dimensions down to the millimeter. A computer and monitor you put in a crate 40 years ago won't work when you pull them out today; however, if the artist gives you guidelines and authority to re-create the work with up-to-date components, it can outlive its original wires and plastic.

In 1998, the Variable Media Initiative at the Guggenheim proposed applying such guidelines specifically to combat technological obsolescence. One of its best-known innovations was later adopted by museums such as the Whitney and archives such as Rhizome. The Variable Media Questionnaire asks creators to choose the most appropriate strategy for dealing with the inevitable slippage that results from translating to new mediums, whether storage, emulation, migration, or reinterpretation. Most brick-and-mortar institutions that collect work in variable media, including digital works but also performances and installations, now incorporate some form of artist interview in their acquisition process.

You don't get any of that with a typical NFT. To date most crypto marketplaces and museums have blithely ignored the past lessons of digital preservation. One of the rare exceptions is the "archival packages" that conservator Regina Harsanyi has prepared for certain galleries based on precedents such as the variable media paradigm--but again, these guidelines are outside of the NFT contracts themselves.

The disadvantage of the variable media approach is that interviewing the artist and assembling guidelines takes time and care--two qualities at odds with today's fast-pasted, pump-and-dump culture of NFT speculation. The advantage is that works preserved in this way are more likely to survive in an authentic form for the appreciation of collectors, artists, and the lay public for decades to come.

Meanwhile, in the absence of a more thoughtful approach to preservation, huge swathes of the digital art currently sold via NFTs will disappear due to abandoned servers or software obsolescence. Even those lucky enough to survive run the risk of losing their original value by mistranslation into an inappropriate new medium when the old one dies. This bleak future awaits NFTs even if the blockchain lives on forever, like a virtual cemetery whose digital tombstones point to art that died because its owner trusted in automated immutability instead of deliberate care.

\section{Could NFTs preserve the spirit of Warhol's digital works?}

Advocates of so-called "web3" often speak of NFTs as a groundbreaking, Internetnative art form. [6] If NFTs are a radical departure from the past, then perhaps it's unfair 
to evaluate them according to the expectations of past legal and archival standards. Art critics of the past have been chastised for applying old standards to new genres [7]; if NFTs chart new artistic territory, perhaps they also chart new territory for social memory. [8]

If NFTs truly are a new preservation paradigm, where would we look to judge their capacity for preserving what matters for digital art? Appropriately enough, we might learn lessons from artists such as Warhol and his contemporaries who pushed the boundaries of what the art market could accept at their time.

\subsection{Democratizing the art world}

According to some observers, Warhol shared with NFTs a promise of democraticizing the art market. Given the success stories bruited about Twitter by creators who can finally pay their rent by selling JPEGs, it's tempting to see NFTs as the realization of Warhol's prophecy that in the future everyone will be famous for 15 minutes. Historian Mike Maizels alludes to a comparable opportunity for new collectors as well as artists, which for Pop art was also connected to new technologies:

Probably the closest art historical analog to the present NFT fervor was the dramatic rise of Pop art in the early 1960s. Artists such as Jasper Johns and Andy Warhol turned suddenly in earnest to colorful, recognizable imagery produced in technological, déclassé media in multiple such as screenprints and lithographs. Intentionally or not, this created an unprecedented volume of stuff to sell to the nouveau riche who had been locked out the Old Master circuit. 50 soup cans supports a lot more market action than one Vermeer. [9]

Warhol trawled mass culture for inspiration. Viewers of every social class could recognize his imagery, from the humdrum Brillo boxes on his pedestals, to the Empire State Building in his tedious 8-hour film, to Marilyn Monroe and the electric chair in his lurid silkscreens. It's tempting to see echoes of Warhol's crass imagery in Beeple's garish juxtapositions of Buzz Lightyear, Baby Yoda, and Pikachu.

\subsection{Business as its own art form}

Of course, new most patrons want the art they collect to persevere, and as we've seen the technology of NFTs has too many legal and technical liabilities to guarantee future access. However, even if your animated Pop-Tart cat won't run in the future, maybe that's not the point of NFTs. Perhaps Warhol's art foreshadowed NFTs because he proved that business itself could be an art form. "Good business is the best art," Warhol claimed, insisting that he wanted to sell shares of his company on Wall Street. [10]

While not a fan of NFTs himself, artist Aram Bartholl draws a parallel between the economic creativity of the NFT phenomenon and Warhol's goal of turning commerce into art. [11] Others have drawn parallels with Warhol's peers who departed from the economic model of their time. Yves Klein, born the same year as Warhol, famously claimed a patent on a particular paint color he called "International Klein Blue." In an even closer precursor to the idea of selling immaterial "tokens" for art, Klein sold Zones of Immaterial Pictorial Sensibility to at least three buyers.

\subsection{Displacing art from its source}

As we've seen, an NFT contract does not typically convey the rights to any media asset, but merely points to a metadata file outside of the blockchain, which itself includes another link to the asset somewhere else on the Internet. This flimsy connection between the crypto-token and its associated image has drawn plenty of scorn from critics of NFTs. But could this just be the latest logical extension of Warhol's trademark displacement of art away from the artist's hand?

Perhaps influenced by his background in commercial illustration, Warhol bucked against the signature brushwork of Abstract Expressionism painters and instead pursued a direction Marcel Duchamp hinted at in his experiments with chance operations, namely distancing artmaking from the aesthetic choices of the artist. [12] Warhol famously 
christened his studio "The Factory" and invited collaborators to fabricate his works. [13] He championed quasi-industrial processes like silkscreening that automated artistic production, as today's creators of PFP (profile picture) NFTs such as Cryptopunks and the Bored Ape Yacht Club auto-generate hundreds of NFTs using algorithms. Warhol even paid a performer to impersonate himself in lectures given at colleges as part of a tour across the country. [14]

In one of his most acerbic affronts to the exaggerated role of the artist's body in $\mathrm{Ab}$ stract Expressionism, Warhol poured urine onto canvases covered with copper-infused paint to create his Oxidation series. How better to improve on Jackson Pollock than by removing the brush - and even the arm - from the equation, effectively sneering, "Look ma, no hands!" Although it might seem that depositing the artist's DNA on the canvas would be the ultimate artist's signature, in fact Warhol invited his assistants and even visitors to The Factory to urinate for him, again thwarting the easy identification of the work with the artist's body. [15] It's not a big stretch between Warhol selling piss and a tennis star selling a patch of skin as an NFT; either way, the carnal specimen isn't the real reason the collector is throwing down money.

Given Warhol's apparent disdain for the artist's hand, it's tempting to conclude he wouldn't have minded that the images sold as NFTs were not in the original format that he "touched" with a mouse in 1985.

\section{Warhol and NFTs: the missing connection}

\subsection{The myth of the businessman artist}

Was the fact that Warhol never got listed on the stock exchange merely a consequence of his being ahead of his time? Would he have jumped at NFTs, the way Klein jumped off a second-story roof in his famous photograph Leap into the Void?

Don't go anointing Warhol and Klein the patron saints of NFTs just yet. It's worth remembering that Klein's leap was a conceptual rather than physical gesture, as the photo was retouched in the darkroom to remove the image of his wife and friend holding a tarpaulin. [16] Similarly, Klein's bid at patenting a signature blue turns out in legal terms to be more of a prank than a precedent. True, Klein deposited a sealed envelope containing his formula at a national institute of industrial property in 1960, but the patent was never awarded. Oil painters may recognize the source of his intense blue as the widely available pigment ultramarine; Klein's "secret recipe" merely bound ultramarine in a high-quality, synthetic resin that can still be purchased from a pharmaceutical company to this day.

As for his Zones of Immaterial Pictorial Sensibility, Klein knew that selling a receipt for a "zone" would simply substitute one commodity for another. Since his goal was to subvert rather than reinforce the art market, he required owners to burn their paper receipt in order to "own" the work itself. Even the artist Mitchell Chan, whose "Digital Zones of Immaterial Pictorial Sensibility" allude directly to Klein's gesture, admits that "Klein drew a clear distinction between ownership of the receipt for the artwork, and ownership of the true 'immaterial value' of the artwork." [17]

As for Warhol's oft-quoted taunt that "Good business is the best art," his biographer Blake Gopnik argues that money was a means, but provocation was the end:

The real, very Warholian creativity came in making the statement at all rather than in trying to realize its claims. Coming up with the conceit of Business Art, that is, let Warhol produce objects and offer them for sale while insisting that the offering, more than the objects, counted as the art. It was the performance that mattered, not its cash results. In the early 1980s, when Warhol was often billed as a full-blown sell-out, he reacted with unusual venom when his print dealer said they were going to be having a chat about Warhol-brand bedlinens. "No. We're not," Warhol told him. "Sonny, I've turned down millions of dollars in deals for sheets and pillowcases and I'm not going to do it for you"....That idea of John Perreault's that "art business can become an efficient comment, not only upon art, but upon business and upon the business culture" implied a "comment" that was also a diss. [18] 
Artists who have mistaken Warhol's moneymaking ventures as commercial rather than artistic gestures have suffered blows to their reputations as a consequence. [19]

\subsection{Copying with connection}

Warhol's disdain at the suggestion that he license his brand for mass-produced merchandise hints at something awry in the analogy between his "art as business" provocation and the get-rich-quick ethos endemic to the NFT discourse. As of this writing, 18,000 freelancers are offering to make NFTs for artists on the online marketplace Fiverr. [20] This might seem like a perfect analog to The Factory, but it's not. Making NFTs for an anonymous buyer at $\$ 10$ a pop isn't some empowering new business model for digital creators. These freelancers are a creative underclass underpinning a speculative market based on buying works with almost no grasp of who the artists are or why they make their work.

The Internet may not have existed in the 1960s, but order-by-phone sure did. Richard Warren Sears started a business selling watches through his eponymous mail order catalogue in 1888; László Moholy-Nagy ordered enameled Telephone Pictures over the phone in 1923; Donald Judd was already delegating the fabrication of his Minimalist sculpture by 1964. [21] Yet Warhol didn't as a rule outsource his production beyond the walls of his studio, and often developed close relations with the people who worked there. Many of these "Warhol superstars" became household names in the arts, from Jean-Michel Basquiat and John Giorno to Mick Jagger and Madonna.

Most Pop artists exploited the existence of an image in one medium to create an artwork in another. The first medium is often duplicable by some technical means, but the second medium is often unique or limited. Roy Lichtenstein transformed the Ben Day dots of mass-produced comics into unique oil and Magna paintings. Inspired by a visit to Warhol's studio, Robert Rauschenberg silkscreened photographs from magazines and newspapers of stop signs and John F. Kennedy, but added paint and collage to create unique works. Warhol may have invested more in printmaking than his Abstract Expressionist predecessors, but he still limited his editions. NFTs fit this pattern, since they are literally defined by a "non-fungible" specification like ERC-721, which replaces infinitely cloneable monkey JPEGs and Spiderman GIFs with unique pointers to them.

The fundamental difference between Pop art and an ERC-721 contract is the connection to the artist. Warhol poked fun at traditional measures of authenticity such as the uniqueness of the product and the involvement of the artist's body in the work. But the key to his artistic ambition was stretching that relationship as far as he could without breaking it. Could a mass-produced item still be a Warhol? Could a work that never touched his hand still be a Warhol? The lynchpin of his career was always his personal mystique. His ghost haunts every work.

\subsection{Copying without connection}

NFTs don't respect that connection to the artist. The variable media paradigm suggests that conserving media art requires change, yes, but that change is a triangulation among past incarnations and the artist's intent. Because they are detached from their referents, NFTs run the risk of creating a separate economy with no regard to the spirit of the original. (Pokemon cards may still bring record sales at auction even if no one actually plays the game anymore.) Christie's Warhol NFTs are doubly detached from their referents, since the referents alluded to in Christie's website aren't the original images anyway.

I'm partly blame for this mess. When he told me about the Amiga discovery back in 2014, Golan Levin, a Carnegie Mellon professor and artist working with the CMU Computer Club, was worried that the Warhol Foundation wouldn't allow the public to see the newly discovered images. They were clearly valuable in both economic and art historical terms, but as digital files they would be infinitely reproduceable if shared online. Rather than bury this important discovery due because of the financial disincentive, I recommended producing versions for public release as "exhibition copies." In museum parlance, an exhibition copy is a duplicate created to stand in for an original artifact that is either too fragile to be showcased in a public setting or unavailable in a format conducive for 
long-term display. That way the Warhol Foundation could have its cake and eat it too, by husbanding its originals while getting the word out through facsimiles.

When museums display exhibition copies, they are honor-bound to declare as much on the wall label. Yet Christie's auction page makes no mention that the images shown on the website and described in the text are altered versions. The point of creating exhibition copies was to preserve the historical value of the originals, but that's lost if the original is concealed behind a facsimile with a glossy makeover.

It's possible that this failed custodianship by the Warhol Foundation was an unwitting lapse due to a misunderstanding about the technology, but the disconnect was deliberate in the case of a different set of Warhol knockoffs. The art collective known as MSCHF (an acronym suggesting the word "mischief") offered a thousand Warhol sketches for sale for $\$ 250$ each, with the catch that all but one are forgeries. On their website, MSCHF rejects the suggestion that Warhol reveled in unlimited reproduction, suggesting instead that multiplication might be a good way to destroy his work.

Ubiquity is the darkness in which novelty and the avant-garde die their truest deaths. More than slashed canvas or burned pages, democratization of access or ownership destroys any work premised on exclusivity. [22]

Speaking of forgeries, Artnet's first item of advice for spotting a fake Warhol urges skeptics to "look for the human touch." [23] Warhol's spectral presence seems to matter even in the immaterial space of a screen. Levin used a similar haptic metaphor for the Amiga files, arguing that every pixel in the originals was "touched by the hand of Warhol." [24]

It seems wrongheaded to apply a tactile metaphor to immaterial bits, but the strength of Warhol's charisma may warrant it. At the Amiga's unveiling, engineer Bob Pariseau did his best to wow mainstream journalists with a demo of its user interface, but the guest who followed his presentation needed no introduction. Warhol's presence live on that stage sufficed to communicate the importance of this new computer. It's also a reason he actually signed these works--an extremely rare occurrence in digital art. The dexterity required to hand-draw a signature on a point-of-sale terminal with a stylus can still be daunting today; imagine being one of the first people ever to use a mouse to sign your name on a digital image. Warhol insisted on trying. [25]

\subsection{Originality counts, even for critiques of originality}

In "What Critics Don't Understand About NFTs," Jonathan Zittrain and Will Marks argue that NFTs are more desirable if disconnected from the original:

The presumption that NFT buyers are being ripped off misses an important paradox of certain digital goods: The less of a link they have to tangible, non-internet stores of value, the higher the price they might command. NFTs' abstraction, their seemingly arbitrary valuation, and even the paltriness of the privileges they convey to their owners are, for now, big selling points, especially to buyers purchasing directly from artists. People have complex reasons for buying things, and NFTs are no exception....An essential part of NFTs' value is that they don't convey anything resembling traditional ownership....they are not buying works, but rather publicly signaling their commitment to the artist, intertwining their respective reputations. They are conspicuously consuming vapors, and the very intangibility of the benefits contributes to the conspicuousness [laying bare] the leap of faith we indulge, wisely or otherwise, when we buy something not because of any innate worth to us but because we expect others to value it later. [26]

Leaps of faith abound in the art world, and Zittrain and Marks are right to identify them as a modus operandi common to collectors who invest in new genres. But Warhol's early collectors never traded on faith in a technology like silkscreens or oxidized copper; they traded on faith in his talent for breaking the boundaries of what could or should be expected from an artist. Pop art's adoption of mass-culture images was later taken to an extreme in the Appropriation art of Sherrie Levine and Richard Prince, who 
rephotographed commercial ads and famous photographs. But that line of investigation reached an artistic dead end. [27]

A handful of artists have explored clever uses of NFTs to extend or critique the idea of creative dissociation, including Kevin Abosch and Ai Wei Wei's 2018 What is Priceless? and Rhea Myer's 2020 Certificate of Inauthenticity. [28] Warhol might have had a creative response to NFTs, but he's not around anymore to make one. That leaves the lion's share of NFTs dissociated by default, the bland by-products of a uniformly automated infrastructure rather than a provocative, conscious choice. As ironic as it sounds, a critique of originality has to itself be original in order to mean something to art history.

As for the exhibition copies that Christie's sold for $\$ 3$ million, there's no Warhol left in them. They've given up the ghost.

\section{Notes}

1. The discovery began around 2013 when new media artist and self-proclaimed computer nerd Cory Arcangel stumbled upon a 1985 Commodore product launch on YouTube showing Warhol painting Debbie Harry's portrait on a brand-new Amiga 1000. Arcangel inferred that the creations resulting from this experiment must have been stored on floppy disks, and that these could have wended their way to the Warhol Foundation after the artist died. Arcangel contacted Carnegie Mellon University's Golan Levin, a distinguished new media artist in his own right, and together with Carnegie Museum of Art curator Tina Kukielski and CMU Computer Club mavens Michael Dille and Keith Bare they divulged a hidden side of one of the most well known artists in history.

2. Angelica Villa, "Christie's Auction of Warhol NFTs Raises Questions of Authenticity Among Experts," ARTnews, 21 May 2021, https://www.artnews.com/art-news/market/Christie's-warhol-nfts-1980s-amiga-sale-1234593542, accessed 30 June 2021.

3. "Your purchase of the lot does not provide any rights, express or implied, in (including, without limitation, any copyrights or other intellectual property rights in and to) the digital asset underlying the NFT other than the right to use, copy, and display the digital asset for your own personal, non-commercial use or in connection with a proposed sale or transfer of the NFT and any other right expressly contained in these Conditions of Sale. For the avoidance of doubt, you do not have the right to distribute, or otherwise commercialize the digital asset, or to represent or imply any sort of sponsorship, endorsement, affiliation, or other relationship with the seller and/or the creator of the digital asset without the prior authorization of the seller or the party(ies) that holds such rights." "Conditions of Sale for Christie's Inc.," Christies.com, https://www.christies.com/pdf/onlineonly/ECOMMERCE\%20CONDITIONS\%20OF\%20SALE\%20-\%20NEW\%20YORK\%206-16-21\%20(002).pdf, accessed 21 February 2022.

4. The tendencies of blockchains to exacerbate climate change, economic inequality, and grift are well documented. For a primer, see Justin Cone, "The skeptics' introduction to cryptoart and NFTs for digital artists and designers," JustinCone.com, 1 January 2021, https://justincone.com/posts/nft-skeptics-guide/, accessed 20 February 2022.

5. Dmitri Cherniak, Ringers (2021), https://www.artblocks.io/project/13, accessed 20 February 2022.

6. Caitlyn Lustig disputes this claim, arguing that web3 is less a new dawn than a "proximal future" that is always promised but never arrives. This situation is also characteristic of pyramid schemes, which require buy-in from new users to fund payouts for early adopters. Caitlin Lustig, "Intersecting Imaginaries: Visions of Decentralized Autonomous Systems," Proc. ACM Hum.Comput. Interact. 3, CSCW, Article 210 (November 2019), https://doi.org/10.1145/3359312, accessed 20 February 2022.

7. Notable examples include Leo Steinberg (for Abstract Expressionism and Pop art), Linda Nochlin (for women artists), and Steve Dietz (for net art).

8. I explore unconventional forms of social memory in my book with Richard Rinehart Re-collection: Art, New Media, and Social Memory (Cambridge: MIT Press, 2014). More at http://re-collection.net, accessed 20 February 2022.

9. Mike Maizels, "The NFT and the Future History of Art," Whitehot Magazine of Contemporary Art, https://whitehotmagazine.com/articles/nft-future-history-of-art/5200, accessed 5 December 2021.

10. Blake Gopnik, Andy Warhol Offered to Sign Cigarettes, Food, Even Money to Make Money ARTnews, 21 April 2020, https://www.artnews.com/art-news/market/andy-warhol-business-art-blake-gopnik-biography-excerpt-1202684403/. Adapted from Blake Gopnik, Warhol (New York: HarperCollins, 2020) 
11. Aram Bartholi, "Blockchain, nfts and smart contracts are not the new medium. The driving force in making art with nfts is a very old one: It is money! Andy Warhol: 'Making money is art, good business is the best art.' The promise of 'getting rich quick!'. Sadly money is the medium here," Twitter, 16 February 2022, https://twitter.com/arambartholl/status/1493941344078811136?s = 12, accessed 20 February 2022.

12. Marcel Duchamp, 3 Standard Stoppages (1913-14), The Museum of Modern Art, New York. https://www.moma.org/collection/works/78990, accessed 20 February 2022.

13. In an article entitled "The Blockchain Is Just Another Way To Make Art All about Money," Oliver Roeder described a co-working space for artists to tokenize their work proposed by Rare Art Labs founder John Zettler. Offering another rhetorical link between Warhol and NFTs, Roeder concluded, "Warhol had his Factory; now Zettler wants his." FiveThirtyEight, 7 March 2018, https://fivethirtyeight.com/features/blockchain-is-just-another-way-make-art-all-about-money/, accessed 20 February 2022.

14. Neil Genzlinger, "Allen Midgette, an Ersatz Andy Warhol, Dies at 82," The New York Times, 18 June 2021, https://www.nytimes.com/2021/06/18/arts/allen-midgette-an-ersatz-andy-warhol-dies-at-82.html, accessed 20 February 2022.

15. "Chemical Reactions," AGO Insider (Art Gallery of Ontario), 13 October 2021, https://ago.ca/agoinsider/chemical-reactions, accessed 20 February 2022. Frank Lloyd Wright believed that architecture was the mother of the arts; before architecture, however, territory was marked by urination, which also encompassed drawing and performance.

16. Jacqui Palumbo, "How Yves Klein Tricked the World with This Iconic Photograph," Artsy, 2 January 2020 https://www.artsy.net/article/artsy-editorial-yves-klein-tricked-iconic-photograph, accessed 20 February 2022. Klein was a judo expert, the first European to achieve a 4th-degree black belt.

17. "Klein drew a clear distinction between ownership of the receipt for the artwork, and ownership of the true 'immaterial value' of the artwork. To acquire the latter, a holder of a receipt for the artwork could participate in a ritual. They met Klein in the presence of witnesses at the River Seine and burned their receipt. Klein then threw half of the gold he received as payment into the river, and the true transaction was complete. For Klein, a true ownership of the artwork meant that the pure artistic sensibility of the piece was completely absorbed, or 'integrated,' into the owner. It was a part of them. Hence no material record would be required. The artwork now belonged to the buyer 'absolutely and intrinsically'....There are three well-documented instances where purchasers of the Zones did participate in this ritual to relinquish their material deed to the artwork in order to gain its immaterial value." Mitchell F. Chan, "Digital Zones of Immaterial Pictorial Sensibility" (published to IPFS), August 2017, pp. 25-26. https://ipfs.io/ipfs/QmcdKPjcJgYX2k7weqZLoKjHqB9tWxEV5oKBcPV6L8b5dD:

18. Gopnik (2020).

19. "With each attempt to monetize his artistic talent - whether through paintings, prints or NFTs - [Damian] Hirst's originality as a conceptual sculptor becomes an ever more distant memory....'Damien was one of the most radical artists of postwar Britain, both as a sculptor and as a thinker,' [collector Ivor] Braka said. But Hirst's subsequent strategy of 'making the maximum amount of money in the shortest time was not the greatest decision,' he added." Scott Reyburn, "Damien Hirst's Medium Is the Art Market," The New York Times, 21 January 2022, https://www.nytimes.com/2022/01/21/arts/design/damien-hirst-nft.html, accessed 21 February 2022.

20. Jon Ippolito, "18,000 freelancers now offer to make NFTs for artists on Fiverr, starting at $\$ 10$. This isn't democracy for digital creators. It's a creative underclass underpinning a speculative market based on buying works with almost no grasp of who the artists are or why they make their work," Twitter, 7 December 2021, https://twitter.com/jonippolito/status/1468282182305210369, accessed 20 February 2022.

21. Lisa Radon, "Donald Judd: Delegated Fabrication," Portland Monthly, 28 April 2010, https://www.pdxmonthly.com/arts-andculture/2010/04/donald-judd-fabrication

22. Michelle Shen, "1,000 Andy Warhol sketches will be sold for $\$ 250$ each. The catch? 999 are forgeries," USA Today, 25 October 2021, https://www.usatoday.com/story/news/nation/2021/10/25/andy-warhol-sketches-sale-250-each-only-onereal/8542832002, accessed 5 February 2022.

23. Richard Polsky, "How Can I Tell If My Warhol Is Fake? Here Are Five Tell-Tale Clues, According to an Expert," Artnet, 5 November 2020, https://news.artnet.com/opinion/how-can-i-tell-if-my-warhol-is-fake-here-are-five-tell-tale-clues-according-toan-expert-1920633, accessed 20 February 2022.

24. Villa (2021). 
25. Except in the rare case of on-chain code, the NFT specification doesn't even require a cryptographic signature of the media file in any of the associated records, despite this being a standard feature of professional preservation software. In this regard, Warhol was more concerned about authenticity than the NFTs that now represent him.

26. Jonathan Zittrain and Will Marks, "What Critics Don't Understand About NFTs," The Atlantic, 7 April 2021, https://www.theatlantic.com/ideas/archive/2021/04/nfts-show-value-owning-unownable/618525/, accessed 12 February 2022.

27. In fact, I recall reading about an artist who tried to one-up the Appropriationists by rephotographing Richard Prince photographs of other people's photographs. I can't recall that artist's name, and I'm betting you can't either.

28. Christie's bait-and-switch doesn't even qualify as a critique. They didn't publicize the difference between the original images and the upscaled ones they pointed to, and they also buried the fact that they weren't selling intellectual property rights at all in the fine print of the conditions of sale. 